\title{
RESEARCH
}

\section{A Pre-matriculation Success Program to Improve Pharmacy Students' Academic Performance at a Historically Black University}

\author{
Mary K. Awuonda, $\mathrm{PhD},{ }^{\mathrm{a}}$ Emmanuel Akala, $\mathrm{PhD},{ }^{\mathrm{a}}$ La'Marcus T. Wingate, PharmD, $\mathrm{PhD},{ }^{\mathrm{a}}$ Salome Bwayo \\ Weaver, PharmD, ${ }^{a}$ Kirsten Brown, PharmD, ${ }^{b}$ Celia Williams-Fowlkes, MEd, ${ }^{a}$ Toyin Tofade, PharmD, MS $^{\mathrm{a}}$ \\ ${ }^{a}$ Howard University, College of Pharmacy, Washington, District of Columbia \\ ${ }^{\mathrm{b}}$ University of Virginia Health System, Charlottesville, Virginia
}

Submitted June 5, 2020; accepted February 15, 2021; published June 2021.

\begin{abstract}
Objective. The Pharmacy Biomedical Preview program is a five-week summer academic reinforcement program held for students entering the Howard University College of Pharmacy. The objective of this study was to evaluate the impact of the program and preadmission factors on pharmacy students' first semester academic performance.

Methods. A retrospective cohort study was conducted of students entering the preview program from 2012 to 2015. The primary outcome assessed was first semester grade point average (GPA). Descriptive statistics of all study variables were conducted. Bivariable analyses were used to compare students by program status. Pearson correlations and point biserial $\mathrm{R}$ were conducted to evaluate which factors were associated with the first semester GPA. Multiple linear regression analysis was used to evaluate whether participation in the preview program predicted GPA during the first semester in pharmacy school after adjusting for other factors. All analyses were conducted using SPSS, version 23, at an alpha of .05.

Results. Incoming overall undergraduate GPA was the strongest predictor of students' first semester GPA in pharmacy school, followed by participation in the Pharmacy Biomedical Preview Program. After adjusting for other factors, mandatory participation in the program was associated with a higher first semester GPA, and voluntary participation in the program was also associated with a first semester GPA that was higher.

Conclusion. Findings from this study indicated that implementation of a pre-matriculation success program at a college of pharmacy in a historically Black institution is a viable strategy to improve students' academic success in the first year.
\end{abstract}

Keywords: health care, STEM, URM, pipeline program, workforce

\section{INTRODUCTION}

National trends in the representation of underrepresented minorities (URMs) in health care professions continues to underscore the need to bolster recruitment and retention efforts for URMs in these careers. ${ }^{1-5}$ Data from pharmacy schools are particularly concerning given the significant decline in applications overall and, in particular, from URM students. ${ }^{6-7}$ While the reasons for the nationwide decline in applications to pharmacy school are not well understood, general factors affecting URM students, such as underachievement in the sciences, poor rates of standardized test taking, poor academic preparation, and lack of acculturation to higher education,

Corresponding Author: La'Marcus T. Wingate, Howard University, College of Pharmacy, $23004^{\text {th }}$ St., NW, Washington, DC 20059. Tel: 202-806-3038. Email: lamarcus.wingate@ howard.edu are likely reducing the number of these students matriculating into pharmacy. ${ }^{4,8}$

Studies have found mixed results regarding the impact of sociodemographic factors on URM students' academic success in the first year of the Doctor of Pharmacy (PharmD) program. Some studies have found significant associations with academic performance in the first year when examining gender, native language, and ethnicity, ${ }^{9-13}$ while others found comparable performance among students regardless of gender, ethnicity, age, or prior educational background. ${ }^{14,15}$ Several studies have reported preadmission factors, such as grade point average (GPA) and completion of the Pharmacy College Admission Test (PCAT), to be important in predicting success in the first year of pharmacy school; however, limited data are available from Historically Black Colleges and Universities (HBCUs), where most students are URMs. ${ }^{16}$ The effectiveness of these programs as 


\section{American Journal of Pharmaceutical Education 2021; 85 (6) Article 8214.}

well as the impact of preadmission criteria among predominantly African-American students have not been well explored. ${ }^{17}$

One possible strategy that may help URM students to perform at higher levels in programs is implementation of academic success programs. In 2009, the Health Resources and Services Administration (HRSA) and the Office of Public Health and Science within the Department of Health and Human Services published a report supporting the implementation of summer enrichment programs and academic programs as opportunities for URM students to improve their academic performance, increase their interest in the health sciences, and support their enrollment in health professions programs. The report concluded that these interventions could have a positive effect on student outcomes. ${ }^{18}$ Few interventions related to these types of academic success programs for pharmacy students have been described in the literature. ${ }^{19,20}$ Of the few published studies, one is by Dirks-Naylor and colleauges, ${ }^{19}$ who described the successful implementation of an academic performance enrichment program (APEP) in a pharmacy program. The study found that students who participated in the program offered as a part of an Integrated Biological Sciences course had a greater increase in their test scores after joining the program compared to students who did not participate. ${ }^{19}$ This program was intended to run alongside the regular curriculum, and only students who had a grade of less than or equal to $73.5 \%$ at any time during the course were enrolled. The academic instruction was provided by second-year pharmacy students who served as tutors. ${ }^{19}$ Similarly, another study by McLaughlin and colleagues $^{20}$ assessed a 3.5 credit, three-week pharmacy bridging course for first year pharmacy students that examined student knowledge and confidence prior to entering the PharmD program. The course consisted of five modules covering applied math, biochemistry, biostatistics, organic chemistry, and physiology. ${ }^{20}$ The modules were designed and implemented by faculty instructors. ${ }^{20}$

The Howard University College of Pharmacy also has an academic success program known as the Pharmacy Biomedical Preview program. This program is similar to an academic performance enrichment program in that in both types of programs instruction is provided by peers, which is in contrast to the pharmacy bridging course in which instruction is provided by faculty. ${ }^{19,20}$ However, the Pharmacy Biomedical Preview program is similar to the pharmacy bridging course in that they both cover five areas of study and are held prior to students starting course work, which distinguishes these programs from academic performance enrichment programs. ${ }^{19,20}$ There is a scarcity of published studies examining the impact of academic enrichment interventions in pharmacy school, especially those that are held prior to matriculation. This study sought to describe and evaluate the impact of preadmission factors and a pre-matriculation success program on pharmacy students' first semester academic performance in a pharmacy school within an HBCU.

\section{METHODS}

A retrospective cohort study of Howard University College of Pharmacy students who entered the program in 2012 to 2015 was conducted. All students who matriculated into the program, whether they were offered unconditional or conditional admission, were included in the study. Students were excluded if they had not enrolled in the first year or had transferred to another institution.

The Pharmacy Biomedical Preview program at Howard University College of Pharmacy was structured as a five-week summer academic reinforcement program targeting preprofessional pharmacy students. Topics covered in the PBP program were anatomy, physiology, microbiology, biochemistry, and pharmaceutical calculations. Approximately three to four hours of instruction was delivered daily from Monday to Friday. The program was designed to offer academic reinforcement of course content that would be covered in the fall semester of the first professional year, including Pharmaceutical Calculations, Structures and Functions in Therapeutics, and Applied Biomedical Sciences. The Structures and Functions in Therapeutics course incorporated anatomy and physiology content, while the Applied Biomedical Sciences course incorporated biochemistry and microbiology content. The program's curriculum was delivered primarily through student instructors who were compensated for their efforts. The student instructor core was normally comprised of six academically strong second or third professional (P2 or P3) year students, with one student assigned to each subject area along with a student coordinator. Each of the students in charge of a subject devoted approximately 20 to 25 hours a week to lecture delivery and preparation and grading assessments. One faculty member was required for general oversight of the program. The student instructors received training in pedagogy. Assessments were in the form of weekly graded quizzes, with a final graded summative assessment administered at the end of the program. Student mentorship on tips for academic success was also included.

Once flagged by the admission committee, conditionally accepted students received a letter from the admissions office informing them that they were required to participate in the Pharmacy Biomedical Preview program. The program also allowed voluntary participation 


\section{American Journal of Pharmaceutical Education 2021; 85 (6) Article 8214.}

of other students that were accepted without conditions. The process of entering the program required a documented acceptance letter and a completed program registration form.

Data for the study were collected from academic records, admission records, and records from the Center of Excellence at the college. The Center of Excellence was responsible for administering the program and offered additional academic enrichment activities within the college, such as free tutoring provided by selected students who had completed courses with high grades. The college's Center of Excellence had been supported with funding from HRSA since 2012. Once aggregated, the data were cross-referenced and de-duplicated. In cases where records such as undergraduate GPA were missing, the data were imputed using additional resources such as the PharmCAS system, which hosts application information for all college applicants. All data were aggregated in Excel before being transported into SPSS (IBM).

The outcome variables assessed in the study were first semester GPA and academic probation during the first year of pharmacy school. Students were placed on probation during the first year if they earned an $\mathrm{F}$ in any class during the first year or had a cumulative GPA below 2.5 at the end of a semester. The covariates included gender, ethnicity, age, previous degrees obtained prior to pharmacy school, undergraduate science GPA at admission, overall undergraduate GPA at admission, PCAT cumulative scores, score on a mathematics examination administered to students during admission, and degree of participation in the program, ie, no participation at all, mandatory participation, or voluntary participation.

Descriptive statistics were conducted using means and standard deviations for continuous variables and proportions for categorical variables. Bivariable analyses, including one-way ANOVAs and chi-square tests, were conducted to examine baseline differences between groups by program status. Bivariable analyses using Pearson and point biserial correlations were conducted to examine associations between study variables and the first semester GPA. For the purposes of point biserial analyses, categorical variables were coded in the following manner: race, $0=$ Nonblack and $1=$ Black; gender, $0=$ female and $1=$ male; undergraduate degree, $0=$ no degree and $1=$ degree; probation during year $1,0=$ no probation and $1=$ probation. With regard to participation status in the Pharmacy Biomedical Preview program, students were categorized into one of three mutually exclusive categories: mandatory participation, voluntary participation, or no participation. Multiple linear regression analysis was used to predict GPA during the first semester in pharmacy school, with the Pearson and point biserial correlation findings guiding the selection of variables in the final model. Multiple logistic regression analysis was used to determine which variables had a predictive effect on probation during the first year in pharmacy school. Multicollinearity effects and regression diagnostics were assessed for multivariable models. All analyses were conducted using SPSS, version 23 (IBM), at an alpha of .05.

\section{RESULTS}

The total sample size consisted of 261 pharmacy students, and students were placed in three categories based on their type of participation in the Pharmacy Biomedical Preview program. Out of all students, 83 (31.8\%) were mandated to take the program as a condition of their admission, $88(33.7 \%)$ voluntarily chose to participate in the program, and $90(34.4 \%)$ did not participate in the program. The demographic characteristics overall and by program status are presented in Table 1 . The majority of students were Black and had earned a degree prior to entering pharmacy school. Differences based on program status were observed in relation to entrance degree, overall GPA at admittance, science GPA at admittance, and cumulative PCAT score. No significant relationship was found between program status and delayed progression $(p=.19)$ or whether a student withdrew from the program or was dismissed during their time in pharmacy school $(p=.79)$. Accordingly, participation in the program did not impact when a student graduated.

Findings from the study demonstrated that PCAT score $(\mathrm{r}=0.20)$, the mathematics interview score $(\mathrm{r}=0.15)$, overall undergraduate GPA $(\mathrm{r}=0.22)$, and voluntary participation in the program $(\mathrm{r}=0.16)$ had a significant positive association with students' first semester GPA as seen in Table 2. In contrast, there was a significant negative association between being placed on probation $(\mathrm{r}=-0.69)$ and no participation in the program $(r=-0.19)$ on students' first semester GPA. There was no significant association found between the first semester GPA and mandatory participation in the program $(\mathrm{r}=0.03)$ in correlation analysis. After including PCAT scores, overall undergraduate GPA, math interview score, program participation status, and entrance year as predictor variables, overall undergraduate GPA and participation in the Pharmacy Biomedical Preview were the strongest predictors of first semester GPA (Table 3). More specifically, students with mandatory participation in the program had a GPA in their first semester of pharmacy school that was 0.30 units higher on average than those students who had not participated in the program after accounting for other potential confounders $(p<.001)$. In addition, students with voluntary participation in the 
American Journal of Pharmaceutical Education 2021; 85 (6) Article 8214.

Table 1. Baseline Characteristics of Students Enrolled in a Doctor of Pharmacy Program and Their Enrollment Status in a Pharmacy Biomedical Preview Program (N=261)

\begin{tabular}{|c|c|c|c|c|}
\hline Variable & $\begin{array}{c}\text { Mandatory PBP } \\
\text { N (\%) }\end{array}$ & $\begin{array}{c}\text { Voluntary PBP } \\
\text { N }(\%)\end{array}$ & $\begin{array}{c}\text { No PBP } \\
\text { N }(\%)\end{array}$ & $p$ value \\
\hline Gender & & & & .72 \\
\hline Male & $35(42.2)$ & $36(40.9)$ & $42(46.7)$ & \\
\hline Female & $48(57.8)$ & $52(59.1)$ & $48(53.3)$ & \\
\hline Race & & & & .23 \\
\hline Black & $56(67.5)$ & $62(70.5)$ & $67(74.4)$ & \\
\hline Asian & $20(24.1)$ & $18(20.5)$ & $16(17.8)$ & \\
\hline White & $3(3.6)$ & $3(3.4)$ & $7(7.8)$ & \\
\hline Other & $4(4.8)$ & $5(5.7)$ & $0(0.0)$ & \\
\hline Year entered & & & & .002 \\
\hline 2012 & $10(12.0)$ & $28(31.8)$ & $36(40.0)$ & \\
\hline 2013 & $25(30.1)$ & $15(17.0)$ & $22(24.4)$ & \\
\hline 2014 & $24(28.9)$ & $24(27.3)$ & $13(14.4)$ & \\
\hline 2015 & $24(28.9)$ & $21(23.9)$ & $19(21.1)$ & \\
\hline Withdrew from program or dismissed & & & & .79 \\
\hline Yes & $4(4.8)$ & $3(3.4)$ & $5(5.6)$ & \\
\hline No & $79(95.2)$ & $85(96.6)$ & $85(94.4)$ & \\
\hline Entrance Degree & & & & .040 \\
\hline No degree & $17(20.5)$ & $17(19.3)$ & $25(27.8)$ & \\
\hline Associates & $1(1.2)$ & $10(11.4)$ & $3(3.3)$ & \\
\hline Bachelors & $63(75.9)$ & $58(65.9)$ & $57(63.3)$ & \\
\hline Masters or higher & $2(2.4)$ & $3(3.4)$ & $5(5.6)$ & \\
\hline Probation Year 1 in Pharm.D. program & & & & .026 \\
\hline Yes & $5(6.0)$ & $7(8.0)$ & $16(17.8)$ & \\
\hline No & $78(94.0)$ & $81(92.0)$ & $74(82.2)$ & \\
\hline Mean age (SD) & $25.16(4.68)$ & $24.74(5.04)$ & $26.42(6.15)$ & .094 \\
\hline Overall Mean GPA at admittance (SD) & $3.01(0.23)^{\mathrm{a}, \mathrm{b}}$ & $3.25(0.39)$ & $3.26(0.39)$ & $<.001$ \\
\hline Mean Science GPA at admittance (SD) & $2.97(0.25)^{\mathrm{a}, \mathrm{b}}$ & $3.26(0.38)$ & $3.28(0.36)$ & $<.001$ \\
\hline First semester pharmacy GPA (SD) & $3.19(0.40)$ & $3.29(0.49)^{\mathrm{c}}$ & $3.03(0.65)$ & .004 \\
\hline Graduating GPA (SD) & $3.14(0.31)$ & $3.24(0.34)$ & $3.19(0.31)$ & .096 \\
\hline Cumulative PCAT (SD) & $58.23(14.6)^{\mathrm{a}}$ & $63.82(15.1)$ & $62.81(14.2)$ & .031 \\
\hline Interview Math Score (SD) & $29.58(4.88)$ & $30.75(5.09)$ & $30.03(5.25)$ & .34 \\
\hline
\end{tabular}

Abbreviations: PBP $=$ Pharmacy Biomedical Preview Program.

a Significant difference between mandatory PBP and voluntary PBP.

b Significant difference between mandatory PBP and no PBP.

c Significant difference between voluntary PBP and no PBP.

program had a GPA that was 0.24 units higher on average than students who had not participated in the program $(p=.001)$. We also observed that a one unit increase in undergraduate GPA resulted in a 0.40 unit increase in first semester GPA after adjusting for other factors $(p<.001)$. The PCAT was a significant predictor but only increased the GPA by 0.008 units for each increase of one unit in the percentile score $(p<.001)$.

A multiple logistic regression analysis was done to examine predictors of academic probation. This model was limited with regard to the number of predictor variables that could be included because of few probation events. After adjustment for composite PCAT scores and overall undergraduate GPA, individuals who did not participate in the program had 5.24 times greater odds of experiencing academic probation during year one compared to students who had mandatory participation in the program, with an odds ratio equal to $5.24(p=.003)$. A one-unit increase in undergraduate GPA led to a decrease in the odds of being on probation in the first year $(p=.038)$.

\section{DISCUSSION}

This study sought to evaluate the effect of preadmission factors and participation in a pre-matriculation success program on students' academic success in the first semester of pharmacy school. To our knowledge this is the first study to examine both these issues at a HBCU. Our 


\section{American Journal of Pharmaceutical Education 2021; 85 (6) Article 8214.}

Table 2. Correlations Between Sociodemographic Characteristics, Academic Preadmission Factors, and Participation in a Pre-Matriculation Success Program with First Semester Grade Point Average in Pharmacy School

\begin{tabular}{lc}
\hline Variable & $\begin{array}{r}\text { Correlation } \\
\text { Coefficient }\end{array}$ \\
\hline Gender & -0.076 \\
Race & -0.016 \\
Age & 0.094 \\
PCAT & $0.21^{\mathrm{a}}$ \\
Overall undergraduate GPA & $0.22^{\mathrm{a}}$ \\
Undergraduate science GPA & 0.074 \\
Math interview score & $0.15^{\mathrm{a}}$ \\
Degree prior to pharmacy school & 0.007 \\
Probation year one of pharmacy school & $-0.69^{\mathrm{a}}$ \\
Mandatory PBP & $0.031^{\mathrm{a}}$ \\
Voluntary PBP $^{\mathrm{c}}$ & $0.16^{\mathrm{a}}$ \\
No PBP $^{\mathrm{d}}$ & $-0.19^{\mathrm{a}}$ \\
\hline
\end{tabular}

Notes: Coding of variables is enumerated in methods

Abbreviations: $\quad \mathrm{GPA}=$ Grade Point Average; $\mathrm{PBP}=$ Pharmacy Biomedical Preview Program; PCAT=Pharmacy College Admission Test

a Statistically significant.

b Mandatory PBP students are those who were mandated to take the PBP program as a condition of their admission.

c Voluntary PBP students are those who volunteered to participate in the PBP program.

d No PBP program are those students who did not participate in the PBP program.

findings suggest that participation in the Pharmacy Biomedical Preview program had a positive impact on students' academic performance. Specifically, the data suggest that participation in the program was associated with increased first semester GPA. Students who voluntarily participated in the program had the highest overall GPA during the first semester, which suggests that even students with relatively strong undergraduate GPAs and PCAT scores may benefit from participation in these types of programs. Our findings were similar to those of two published studies, one evaluating a pre-matriculation and the other a post-matriculation academic support program..$^{19,20}$

The existing evidence on pre-matriculation and postmatriculation programs in pharmacy schools suggests they are useful in improving student success. The benefit of our program as shown in this study is particularly important given the decline in URM students matriculating into PharmD programs. The 2018 AACP summary enrollment data showed the smallest annual percent increase $(0.8 \%)$ in enrollment in pharmacy professional degree programs was among Black/African American students. ${ }^{21}$ The yearly incremental rate was the smallest observed in the past decade (range, 3.5\%-7.3\%). Another evaluation by AACP that investigated trends in acceptance rates found that among 16,246 applicants there was a lower acceptance rate of URM students. ${ }^{21}$ Collectively, these trends signal a slowing matriculation rate into Doctor of Pharmacy programs for URM students. These findings underscore the importance of supporting and developing pre-matriculation success programs in pharmacy schools at HBCUs where a large number of URM students seek training.

Our study found that pre-admission GPA was an important predictor of GPA in the first semester. These findings are in alignment with other studies. ${ }^{22-27}$ Of the studies conducted in non-historically black institutions, GPA had a high correlation with first professional year GPA, better grades in pharmacy school, decreased odds of being in the bottom quartile, and decreased odds of poor student performance. $22,23,25,26,28$ The studies conducted at HBCUs or that did a subgroup analysis on Black students showed similar trends. ${ }^{16,17,24,27}$ Collectively, these findings continue to support the use of GPA as a preadmission criteria.

Our study found a relatively small but significant predictive effect of the PCAT composite score on first semester performance. Based on the magnitude of the beta coefficient, the impact of the PCAT composite score in our studies was less than that seen in other studies, which noted more impactful associations. ${ }^{9,12,29-33}$ Previous studies report mixed findings regarding the impact of the PCAT on academic performance in the first year for some student groups. For instance, Tejada and colleagues did not find any association between overall PCAT score and first year didactic performance among African American students, but did find associations between the PCAT and the didactic performance of second and third year PharmD students. ${ }^{17}$ Dutta and colleagues found that the PCAT chemistry and quantitative scores had a statistically significant relationship with GPA among first year pharmacy students at an HBCU, however the composite PCAT score was not found to have a significant relationship with the first year GPA in this analysis. ${ }^{16}$ Other findings have also suggested that students' PCAT performance may vary based on other factors beyond academic capability. For instance, Vongvanith and colleagues showed that URM students tend to have lower baseline PCAT scores compared to their non-URM counterparts, with the highest performance on PCAT scores related to parental attainment of higher education and applicant background education listed as higher than a bachelor's degree. ${ }^{29}$ Related trends have also been observed in scores on standardized tests for admission to medical school. Capers found that graduation rates and residency entry did not differ for 


\section{American Journal of Pharmaceutical Education 2021; 85 (6) Article 8214.}

Table 3. Multivariate Linear Regression Model to Evaluate Predictive Effect of Academic Preadmission Factors and Participation in a Pre-Matriculation Success Program on GPA during First Semester in Pharmacy School

\begin{tabular}{llcccccccc}
\hline Variables & B & $\begin{array}{c}\text { Standard } \\
\text { Error }\end{array}$ & Beta & T & Significance & $\begin{array}{c}\text { Zero-order } \\
\text { Correlations }\end{array}$ & $\begin{array}{c}\text { Partial } \\
\text { Correlations }\end{array}$ & Tolerance & VIF \\
\hline Constant & 0.93 & 0.36 & & 2.60 & 0.010 & & & & \\
PCAT Cumulative & 0.008 & 0.002 & 0.21 & 3.28 & $<0.001$ & 0.21 & 0.22 & 0.85 & 1.19 \\
Overall Undergrad GPA & 0.41 & 0.086 & 0.30 & 4.76 & $<0.001$ & 0.22 & 0.29 & 0.86 & 1.16 \\
Math Interview Score & 0.009 & 0.006 & 0.088 & 1.45 & 0.15 & 0.15 & 0.091 & 0.79 & 1.26 \\
Mandatory PBP & 0.30 & 0.078 & 0.26 & 3.84 & $<0.001$ & 0.032 & 0.24 & 0.62 & 1.61 \\
Voluntary PBP & 0.24 & 0.071 & 0.21 & 3.37 & 0.001 & 0.17 & 0.21 & 0.74 & 1.34 \\
2013 Entrance Year & -0.21 & 0.084 & -0.16 & -2.45 & 0.015 & -0.27 & -0.15 & 0.64 & 1.55 \\
2014 Entrance Year & 0.063 & 0.087 & 0.050 & 0.72 & 0.47 & 0.094 & 0.046 & 0.61 & 1.65 \\
2015 Entrance Year & 0.28 & 0.084 & 0.23 & 3.37 & 0.001 & 0.28 & 0.21 & 0.64 & 1.57 \\
\hline
\end{tabular}

R-square $=0.274$

Abbreviations: $\mathrm{GPA}=$ Grade Point Average, $\mathrm{PBP}=$ Pharmacy Biomedical Preview Program, PCAT $=$ Pharmacy College Admission Test, $\mathrm{VIF}=$ Variance Inflation Factor

African-American medical students in spite of them having lower MCAT scores. ${ }^{34}$ While the findings show that taking the PCAT may benefit some students, a number of schools are no longer requiring it for admission. This is likely due to the increasingly competitive landscape of pharmacy education, resulting in pressures on some institutions to fill their first-year classes.

There are some limitations to this study that are important to note. As many as five students each year had to participate in the PBP program online rather than face-to-face because of extenuating circumstances. The impact of the program on these students may have been attenuated because they missed some of the in-person interactions that took place in the program. Whether the program was delivered online or in person was not controlled for in the analyses, so caution should be used when applying the results of this study to those where the program is only administered virtually. In addition, other academic enrichments offered to students through the $\mathrm{COE}$, such as tutoring, were not controlled for in statistical analyses, so this may be a potential limitation. However, tutoring is offered to all students within the college without regard to their participation in the program. The model predicting probation during year one was based on a few events because only 28 students had academic probation during this time period. As a result, the model could not include all potential confounders, so caution should be used when interpreting this result because of the limited sample size.

\section{CONCLUSION}

Our study found that a pre-matriculation program, the Pharmacy Biomedical Preview, which was taught and administered to first year PharmD students primarily by their peers enrolled in the second and third years under faculty guidance, can be a useful initiative to implement at colleges of pharmacy to help students who have lower baseline pre-admission scores. The pre-matriculation program also benefitted incoming students with more robust academic records who voluntarily chose to participate. This was the first study to assess the benefit of a prematriculation program at a college of pharmacy with a student body consisting of mostly URM students. However, results from other studies suggest a program of this nature may be beneficial in other institutions where most students are not URMs. ${ }^{19,20}$ Therefore, additional studies are warranted to explore the impact of a prematriculation program on students at other institutions.

\section{ACKNOWLEDGMENTS}

This project was funded in part by the HRSA Center of Excellence Grant and by the National Institute on Minority Health and Health Disparities of the National Institutes of Health.

\section{REFERENCES}

1. Castillo-Page L. Association of American Medical Colleges Diversity in Medical Education: Facts \& Figures 2012. https://www. aamc.org/media/9951/download. Published Fall 2012. Accessed May 26, 2021

2. Carlisle DM, Gardner JE, Liu H. The entry of underrepresented minority students into United States medical schools: an evaluation of recent trends. Am J Public Health. 1998;88(9):1314-1318.

3. Okwuje I, Anderson E, Siaya L, Brown LJ, Valachovic RW. U.S. dental school applicants and enrollees, 2006 and 2007 entering classes. J Dent Educ. 2008;72(11):1350-1391.

4. Alonzo N, Bains A, Rhee G, et al. Trends in and barriers to enrollment of underrepresented minority students in a pharmacy school. Am J Pharm Educ. 2019;8 (7):Article 6925. 


\section{American Journal of Pharmaceutical Education 2021; 85 (6) Article 8214.}

5. White C, Conway JM, Davis PK, et al. AACP Special Taskforce white paper on diversifying our investment in human capital. Am J Pharm Educ. 2017;81(8): Article S13.

6. Schoelles-Williams J, English DE 2nd, Godwin DA, et al. Report of the 2018-2019 Student Affairs Standing Committee. Am J Pharm Educ. 2019;83(10):7656.

7. Academic Pharmacy's Vital Statistics. https://www.aacp.org/ article/academic-pharmacys-vital-statistics. Published January 2021. Accessed May 26, 2021.

8. Campaign for Action. Missing persons: Minorities in the health professions, a report of the Sullivan Commission on Diversity in the Healthcare Workforce. https://campaignforaction.org/resource/ sullivan-report-diversity/. Accessed May 26, 2021.

9. Meagher DG, Pan T, Perez CD. Predicting performance in the firstyear of pharmacy school. Am J Pharm Educ. 2011;75(5):Article 81.

10. Bandalos DL, Sedlacek WE. Predicting success of pharmacy students using traditional and nontraditional measures by race. Am J Pharm Educ. 1989;53:145-148.

11. Chisholm M, Cobb H, Kotzen JA. Significant factors for predicting academic success of first-year pharmacy students. Am J Pharm Educ. 1995;59:364-370.

12. Kelly KA, Secnik K, Boye ME. An evaluation of the pharmacy college admissions test as a tool for pharmacy college admissions committees. Am J Pharm Educ. 2001;65(3):225-230.

13. Wu-Pong S, Windridge G. Evaluation of pharmacy school applicants whose first language is not English. Am J Pharm Educ. 1997;61(1): 61-66.

14. Carroll CA, Garavalia LS. Gender and racial differences in select determinants of student success. Am J Pharm Educ. 2002;66(4):382-387. 15. Ried LD, Byers K. Comparison of two lecture delivery platforms in a hybrid distance education program. Am J Pharm Educ. 2009;31 (5):Article 95.

16. Dutta AP, Wutoh AK, Williams C, Ofosu JR. Predictors of academic success at a historically black school of pharmacy. J Pharm Teach. 2002;10(2):1-14.

17. Tejada FR, Parmar JR, Purnell M, Lang LA. Admissions criteria as predictors of academic performance in a three-year pharmacy program at a historically black institution. Am J Pharm Educ. 2016;80(1):Article 6. 18. U.S. Department of Health and Human Services, Health Resources and Services Administration, Bureau of Health Professions, \& Office of Public Health and Science, Office of Minority Health. April 2009. Pipeline programs to improve racial and ethnic diversity in the health professions: an inventory of federal programs, assessment of evaluation approaches, and critical review of the research literature. Rockville, MD. https://aapcho.org/wp/wp-content/uploads/2012/11/Pipe lineToImproveDiversityInHealthProfessions.pdf. Accessed May 26, 2021. 19. Dirks-Naylor AJ, Cook C, Nhean P. Development and assessment of an academic performance enrichment program for low performing, first year pharmacy students. Adv Physiol Educ. 2019;43:259-265. 20. McLaughlin JE, Khanova J, Persky A, Hathaway N, Cox W. Development, implementation, and outcomes of a three week pharmacy bridging course. Am J Pharm Educ. 2017;81(7):Article 6313.
21. AACP Application reports. AACP's Profile of Pharmacy Students, Fall 2001-2020. https://www.aacp.org/research/institutionalresearch/student-applications-enrollments-and-degrees-conferred.

Accessed May 26, 2021.

22. McCall KL, Allen DD, Fike DS. Predictors of academic success in a doctor of pharmacy program. Am J Pharm Educ. 2006;70(5):Article 106.

23. Hansen DJ, Mort JR, Brandenburger T, Lempola A. Relationship of prepharmacy repeat course history to students' early academic difficulty in a pharmacy curriculum. Am J Pharm Educ. 2015;79(10): Article 154.

24. Allen RE, Diaz C, Gant K, Taylor A, Onor I. Preadmission predictors of on-time graduation in a doctor of pharmacy program. Am J Pharm Educ. 2016;80(3): Article 43.

25. Schlesselman LS, Coleman CI. Predictors of poor student performance at a single, Accreditation Council for Pharmacy Educationaccredited school of pharmacy. Curr Pharm Teach Learn. 2011;3(2): 101-105.

26. Schauner S, Hardinger KL, Graham MR, et al. Admission variables predictive of academic struggle in a PharmD program. Am JPharm Educ. 2013;77(1): Article 8.

27. Charupatanapong N, Richard A. Predicting the academic performance of pharmacy students at a predominantly black institution. $J$ Pharm Teach 1993;4(1):21-33.

28. Alston GL, Battise DM, Neville MW. A 10-year study of the academic progress of students identified as low-performers after their first semester of pharmacy school. Am J Pharm Educ. 2016;80(7): Article 118.

29. Vongvanith VV, Huntington SA, Nkansah NT. Diversity characteristics of the 2008-2009 pharmacy college application service applicant pool. Am J Pharm Educ. 2012;76 (8):Article 151.

30. Allen DD, Bond CA. Prepharmacy predictors of success in pharmacy school: grade point averages, pharmacy college admissions test, communication abilities, and critical thinking skills. Pharmacotherapy. 2001;21(7):842-849.

31. Hardigan PC, Lai LL, Arneson D, Robeson A. Significance of academic merit, test scores, interviews, and the admissions process: a case study. Am J Pharm Educ. 2001;65(1):40-44.

32. Kuncel NR, Credé M, Thomas LL, Klieger DM. A meta-analysis of the validity of the Pharmacy College Admission Test (PCAT) and grade predictors of pharmacy student performance. Am J Pharm Educ. 2005;69(3):Article 51.

33. Meagher DG, Lin A, Stellato CP. A predictive validity study of the Pharmacy College Admission Test. Am J Pharm Educ. 2006;70(3): Article 53.

34. Capers Q 4th, Way DP. Academic and post-graduate performance of African American medical students by category of premed institution: historically black vs. predominantly white institutions. $J$ Health Care Poor Underserved. 2015;26(3):617-630. 